\title{
The Relevant Roles of Plastic and Orthopedic Surgery in Hand Salvage
}

\author{
Bassam Ahmed Almutlaq1*, Mohammad M. Al-Qattan'2, Majid Zannon Alturkstani3, \\ Rakan Fraih Almuazzi' ${ }^{1}$ Abdulkarim Saleh Alkhateeb ${ }^{1}$, Ayman Talla Talla1, \\ Muqbil Sayer Alshammari' ${ }^{1}$, Hussain Gadelkarim Ahmed ${ }^{1}$ \\ ${ }^{1}$ College of Medicine, University of Hail, Hail, KSA \\ ${ }^{2}$ Division of Plastic Surgery, Head of Research Centre, College of Medicine, King Saud University, Riyadh, KSA \\ ${ }^{3}$ Batterjee Medical College, Jeddah, Saudi Arabia \\ Email: `hussaingad1972@yahoo.com
}

How to cite this paper: Almutlaq, B.A., Al-Qattan, M.M., Alturkstani, M.Z., Almuazzi, R.F., Alkhateeb, A.S., Talla, A.T., Alshammari, M.S. and Ahmed, H.G. (2018) The Relevant Roles of Plastic and Orthopedic Surgery in Hand Salvage. Modern Plastic Surgery, 8, 29-43.

https://doi.org/10.4236/mps.2018.82005

Received: February 5, 2018

Accepted: April 7, 2018

Published: April 10, 2018

Copyright () 2018 by authors and Scientific Research Publishing Inc. This work is licensed under the Creative Commons Attribution International License (CC BY 4.0).

http://creativecommons.org/licenses/by/4.0/

\begin{abstract}
Over the recent past few years, there is a huge innovation in plastic surgery and orthopedic surgery through implantation of new techniques, which enabled a great level of success in hand salvage. Conditions such as trauma, tumor, sepsis, or vascular disease, may necessitate hand salvage. The most frequent argument among surgeon from different subspecialties (orthopedics, plastics, trauma, and vascular surgery) are characterized by in what way each one can do his own part of the salvage operation, be it bony fixation, revascularization, or soft-tissue coverage, but none of them is sure whether it should be endeavored. What is necessary in such clinical situations is an interdisciplinary team attitude led by individual or groups of clinicians who are conversant not only with their identifiable subspecialized skills but also with those of their coworkers and the consequences accompanying the joined efforts at hand salvage. The perception of orthoplastic surgery is based on such an indication, where the integrated skills and techniques of the orthopedic surgeon and reconstructive microsurgeon are performed in recital to direct efforts concerning hand salvage or choose against it when it is not designated. The current article reviews the roles of orthopedic and plastic surgery and how this team can deal with the existing techniques to improve outcomes in hand salvage surgery.
\end{abstract}

\section{Keywords}

Hand Salvage, Plastic Surgery, Orthopedic Surgery, Hand Transplantation, Prosthetic Fitting

\section{Introduction}

The loss of hand and upper limb is an upsetting, life changing incident. Hands 
are essential body part to our development and psychological comfort, and represent a vital role in the determination of the individual's professional career [1] [2] [3].

Traumatic hand injury represents one of the greatest distressing injuries [4] [5] [6] [7]. These injuries are frequently caused by different injurious means, but the crush injuries are the most apparent and can lead to significant tissue impairment [6]. The relationship of crushing with other processes such as, elongation, torsion, gives extra harmfulness and represents a relative contraindication for replantation [7].

Hand reconstruction after surgical extirpation is critical to restoration of both structure and function. Hand reconstruction has exceptional challenges because of its complex anatomy and function [8].

Efforts to reconstruct this complicated organ have been emerging over several decades in both the fields of surgery and rehabilitation [9] [10]. The simultaneous progresses of hand transplantation and prosthetic limbs have empowered diverse choices for patients with limb loss. Each option has exclusive set of benefits and weaknesses, however amazingly direct judgement at a comparable level of amputation has not yet been achieved [11]. This is particularly valuable as signs for each treatment must be sensibly measured depending on level of amputation, profession, age and patient's expectations [12].

Hand salvage that concentrates on an ideal functional retrieval necessitates an important awareness of the surgical potentials that plastic and reconstructive surgeons transport to the table. As an integral part of the team, plastic surgeons have established innovative approaches that have much enhanced the proportions of hand salvage [13]. Additional fellows of this team comprising Vascular, Orthopedic surgeons as well as physical therapists and wound care team, play an energetic part in not only being capable to categorize approaches that treat upper limbs at risk, but also decreasing related morbidity and mortality. In this review, we will discuss the different options for hand reconstructions with particular stress on transplantation and prosthetics for upper limb amputees in general, as well in regard to the roles of the orthoplastic team to improve outcomes in hand salvage surgery.

\section{Hand Orthopedic Surgery}

Hand surgeons are orthopedic, plastic, or general surgeons who have extra training in surgery of the hand. Hand surgery is the field of medicine that deals with problems of the hand, wrist, and forearm. Hand surgeons are especially skilled to operate hand conditions when needed. Many hand surgeons are also experts in diagnosing and caring for shoulder and elbow problems [14]. Hand surgeons can do a varied operations include fracture repairs, releases, transfer and repairs of tendons and reconstruction of injuries, rheumatoid deformities and congenital defects. They also perform microsurgical reattachment of amputated digits and limbs, microsurgical reconstruction of soft tissues and bone, 
nerve reconstruction, and surgery to recover function in paralyzed hand [15].

Injuries to the hand with loss of joints, tendons, nerves, and soft tissue may need complicated, advanced reconstructive procedures to accomplish a satisfactory functional and aesthetic result [16].

Acquired upper extremity amputations beyond the finger can have considerable physical, psychological, social, and economic outcomes for the patient. The hand surgeon is one of a team of specialists in the care of these patients, but the surgeon plays an important part in the surgical management of these injuries. The performance of a successful amputation at each level of the limb permits supreme usage of the remaining extremity, with or without a prosthesis, and reduces the known complications of such injuries [17].

Traumatic upper extremity amputation is a life-altering incident, and salvage of function depends on accurate surgical management and postoperative rehabilitation. Several injuries necessitate amendment amputation and postoperative prosthesis fitting. Attention should be taken to preserve maximal length of the limb and motion of the residual joints. Skin grafting or free tissue transfer may be necessary for coverage to permit protection of length. Prompt prosthetic fitting within 30 days of surgery should be executed so the amputee can start rehabilitation while the wound is healing and the stump is maturing. Multidisciplinary care is important for the whole care of the patient after a traumatic amputation of the upper limb [18].

Treatment of complex hand trauma comprises sufficient debridement of non-viable tissue, early reconstruction, and careful choice of different existing surgical techniques tailored to patients' requirements and needs. Debridement of all necrotic tissue is important before any attempt at reconstruction. Surgeons should also deliberate cosmetic outcomes of the reconstructed hand and donor-site morbidity. For best outcomes reconstruction should be done promptly, with appropriate early postoperative therapy [4].

There has been augmented interest in and experience with doing numerous surgical techniques on the hand and the wrist employing local anesthesia in un-sedated patients. These surgical techniques can be safely implemented on an outpatient basis. Practice has revealed that the strategic usage of local anesthesia with epinephrine is safe and, in procedures such as tendon repair or transfer, allows intra-operative control of whole motion and function [19].

\section{Historical Development}

Since the first successful reconnection of an amputated arm by Chen et al. in 1962, replantation has come to be a feasible choice in nominated cases of upper limb amputation [20]. At first, the more frequent worry was for the replant to persist viable. By developed (micro) surgical procedures and instrumentation, replantation has turned out to be a technically trustworthy practice [21] [22]. Currently, the anxiety has moved just before attaining adequate functional retrieval with a satisfactory cosmetic outcome [23] [24] [25]. 
Conventionally, prosthetics have made the basis of treatment for upper extremity amputees. Simple body-powered prosthetics are cost effective, but patients frequently castoff them due to discomfort, weight, and imperfect practicality [26]. The new-fangled forms of myoelectric prostheses feature enhanced voluntary control and are proficient of additional complicated and powerful motion, but are remarkably more costly, less resilient, and remarkably heavier than a body-powered prosthesis.

As part of the promptly emerging field of vascularized composite allotransplantation (VCA), hand and upper extremity transplantation has the prospective to replace the lost hand or arm with a closely alike sensate limb capable of complex employment. Supposedly, by transplanting the whole part beside its nerves, blood vessels, muscle and tendon units, and bone, VCA can achieve reconstructive outcomes greater to those of the most innovative surgical procedures or prosthetic novel tools. The eventual aim is replacement of the misplaced limb with one that is approximately identical in both function and look. The prospective benefits over traditional reconstruction and prosthetics are clear, but assumed the risks of enduring immunosuppression, the elevated financial cost, and other essential factors, these operations are kept for cases categorized as severe psychological and physical disability.

As hand transplantation has come to be more common, many significant problems have appeared. These comprise optimization of the immunosuppressive regimen, founding outcomes processes that are appropriate with these operations, refining criteria for patient inclusion, reducing costs, enhancing operative productivity, and improving re-innervation of the graft.

Hand transplantation holds numerous benefits over prosthetic rehabilitation. The lost hand is replaced with one of alike skin color and size. Responsiveness, voluntary motor control, and proprioception are returned to a better degree, and afford superior dexterousness and function than prosthetics. The chief inadequacies of transplantation comprise the risks of immunosuppression, the problems of rejection and its treatment, and elevated cost. Hand and upper limb transplantation represents the most frequently implemented surgery in the developing area of VCA. As upper limb transplantation and VCA have grown more prevalent, several significant challenges and arguments have appeared. These include: refining signs for transplantation, optimizing immunosuppression, establishing appropriate criteria for observing, diagnosing, and treating rejection, and regulating outcome events [27].

Combined tissue transplantation and new advances in the area of prosthetics have released new frontiers in the rebuilding of function among hand amputees. Nowadays it is likely to re-establish hand function in affected individuals; conversely, the signs, benefits, and limits for either hand transplantation or prosthetic fit need careful consideration depending on the level and degree of the upper limb damage. Hand transplantation permits inclusive hand function to be repaired, nonetheless compound tissue transplantation present with shortcomings, forming this process a debatable issue in the hand surgical public. On the 
other hand, prosthetic limb replacement embodies the better care for hand amputees, but with limitations of function, sensation, and practice. The indication for hand transplantation or prosthetic fitting powerfully depends on the degree of amputation [11].

\section{Hand Transplantation}

Hand transplantation remains an infrequent practice, and has been employed at various institutions around the world. Surgical procedures, recipient co-morbidities, degree of amputation, and immunosuppressive regimens vary broadly.

Successful hand transplantation replaces the misplaced portion with a limb that is still, worn continually, never exhausted, appealingly fair, fine to touch and hold, and with the self-mending abilities of the biologic tissue. Hand transplantation in addition to restoration of motor function, it allows a sense of touch, bodily integrity, possession, and naturalness [28]. Although functional results are not stated as constantly, diverse groups display excellent and durable outcomes [29].

The first known hand transplantation was achieved in Ecuador in 1964, however the hand was removed after two weeks later [30]. This was because of inadequate immunosuppressive treatment resulting in rejection [31]. Advances in immunosuppressive regimes employed in solid organ transplantation stimulated additional hand transplantation efforts. Later on, the first successful hand transplant in a below-elbow amputee in 1998 was performed in France [32]. Although, this hand stayed viable for 29 months, but the patient botched to safeguard the necessary immunosuppressive medication leading to chronic rejection, hand failure and eventually amputation [33]. Still, reconstructive transplantation has an exceptional prospective of not only repairing the motor skills related to the hand, but also sensation and self-perception [34]. Essential issues associated with hand transplantation comprise the edges and borders of medical intervention, the possible advantages of the procedure, the consideration of risk and supposed risk, the medical and psychological choice, preparation, and managing of patients [35].

The inclusive data from the International Registry on Hand and Composite Tissue Transplantation (IRHCTT) [36] has reported data on series transplants including bilateral and unilateral cases [36] [37]. The follow-up time extended from 6 months to 13 years. The majority (57.9\%) of transplants were done at the wrist level, and all patients received postoperative immunosuppressive therapy containing tacrolimus, mycophenolate mofetil, and a steroid. Induction was made with mono- or polyclonal antithymocyte antibodies in all cases [37]. The IRHCTT found that $85 \%$ of VCA recipients experienced an occurrence of acute rejection within 1 year of transplant. In some patients, rejection was linked to periods of non-obedience with medication or a scheduled shrinkage in immunosuppressive treatment [36]. Some cases revealed more than one episode of rejection, nevertheless, all cases of rejection fixed with treatment. Treatment of 
rejection commonly involved cumulative the dosages of the patient's immunosuppressive drugs and/or using intravenous steroids. The 2011 IRHCTT report also revealed that metabolic problems experienced in $90 \%$ (35 of 39) of cases getting a hand transplant, whereas opportunistic infections happened in $77 \%$ of the patients [37].

All cases with surviving allografts established protective sensation. Of these cases, $90 \%$ established tactile sensibility and $82 \%$ settled discriminative sensibility [37]. Motor salvage, as anticipated, continues in a proximal to distal direction, with extrinsic salvage taking place first. Intrinsic salvage happens between 9 - 15 months, relying on the level of transplant, which was confirmed by EMG (electromyelogram). Some studies have reported that continuing motor and sensory recovery in hand transplant patients as late as 5 years after surgery [38]. According to update from the IRHCTT, patients restored satisfactory motor function to permit them to implement most activities of daily living, comprising eating, driving, grooming, and writing. In long-term follow-up of 8 and 6 years, 2 patients from the Louisville program were both capable to return to work, and both showed higher functional scores than would be expected with prostheses [39]. To a extent, the level of transplant may decide how much motor and sensory function improves after surgery, with enhanced results anticipated in more distal transplants. Nevertheless, a limited number of above-elbow transplantations have been done, with sensible outcomes [40] [41].

To validate the risks of immunosuppression and surgery, patients getting hand transplants must prove better-quality of life as well as better function. Up to the present time, this critically essential area leftovers less reported in the hand transplant literature. In a study reviewed 27 articles that reported quality of life measures in hand transplant receivers. Results were evaluated applying either the Disabilities of the Arm, Shoulder, and Hand (DASH) score, the Hand Transplant Score System (HTSS). The majority of cases showed a progress in quality of life as assessed by these certified devices, whereas other studies reported a qualitative enhancement in quality of life, public acceptance, and look [42]. The IRHCTT now uses the DASH and HTSS scores to assess quality of life values. HTSS scores averaged 52 at 1 year and 88 at 10 years after transplant (in the HTSS score, 100 is the highest possible score). DASH scores averaged 38 at 1 year and 16 at 10 years post-transplant (in the DASH score, 0 is the best possible score) [36]. Presently, the factual advantage and psychological outcomes of hand transplantation are poorly understood. Prospective research should develop validated devices that precisely measure the variation in quality of life among these patients.

\section{Immunosuppression}

Avoiding the recipient from rejecting the cutaneous part of the complex allograft has historically needed high doses of multidrug immunosuppressive therapy, and worry over the long-standing special effects of such therapy has been a main impairment to the evolution of hand transplantation [43]. 
As stated formerly, existing immunosuppressive therapy commonly involves a multidrug regimen of tacrolimus, mycophenolate mofetil, and a steroid. Induction therapy, intended to diminishing the recipient's immune response and preventing acute rejection, is commonly given in a number of doses, and characteristically is either a polyclonal or monoclonal antibody directed against thymocytes. These therapies have been derived from protocols that are well well-known within solid organ transplantation [44].

\section{Nerve Regeneration}

Unlike solid organ transplants, a composite allograft must survive, and function well to be considered successful. In the upper extremity, nerve regeneration developments at approximately $1 \mathrm{~mm}$ per day [45]. For proximal transplants, this slow speed of growth means that distal muscles may develop fibrosis and useless well before they can be re-innervated. This may compromise the whole functional consequence of an otherwise effective transplant. This is a major cause why proximal forearm and above-elbow transplants continue debated. Therefore, supplementing nerve regeneration, whether through cell-based or pharmacologic mechanisms, has come to be another substantial scope of request [27].

A new bulk of knowledge turned into a common property related to the micro- and macroanatomic structure of peripheral nerves, the process of nerve regeneration, and the technical conditions of nerve reconstructive operations. This knowledge is a prerequisite for hand surgeons to perform their nerve reconstructive operations on a contemporary high level with an optimal result [46]. In nerve injury with nervous gap, no restitution method was found better than the autograft, however, it has the disadvantage of damaging a normal nerve to be used as a graft. Platelet-rich plasma (PRP) is a possible filler material for vein grafts used as conduits for nerve regeneration, preventing its collapse, and providing growth factors and osteoconductive proteins [47]. Long-term follow-up data of digital nerve reconstructions with nerve conduits are limited. Furthermore, it is not known whether nerve regeneration after tubulization is terminated after 12 months, or whether improvement can be expected after this period of time. Notably, evidence was provided that the long-term recovery of sensibility after digital nerve tubulization depends on the nerve gap length with better results in those $<10 \mathrm{~mm}$. Nerve regeneration after tubulization seems not to be terminated after 12 months [48].

Hand transplantation turn out to be a progressively common means of providing life-repairing treatment to patients stricken with devastating effects and disabling conditions. Elevated rates of incipient success, together with emergent worldwide interest in VCA, have led to increasing overall numbers of global transplants. However, there are a number of important challenges need be addressed in order to render hand transplantation to become accepted in the same way that solid organ transplants have. Clinically, better outcome studies and accepted standards of clinical success must be established. At the same time, clearer 
indications for these surgeries are needed. At present, the lifelong requirement for high dose immunosuppression and its associated risks bring a major obstacle to growth.

\section{Bone Lengthening}

Methodological clarifications of Prof. G.A. Ilizarov are the core stone of the modern bone lengthening and reconstruction surgery. They have been recognized in the orthopaedic world as one of the supreme contributions to treating bone pathologies. The Ilizarov technique of transosseous compression-distraction osteosynthesis has been extensively practiced for managing bone non-union and defects, bone infection, congenital and posttraumatic limb length discrepancies, hand and foot disorders. The optimal disorders for employing distraction and compression osteogenesis were established by several experimental studies that Prof. G.A. Ilizarov systematized and supervised at a huge orthopedic research institute in Kurgan. The tension stress influence on regeneration and growth of tissues was carefully studied with radiographic, histological and biochemical approaches. The influence of the Ilizarov technique on the development of bone lengthening and reconstruction surgery could be known as revolutionary [49].

Distraction osteogenesis is a technique of stimulating the growth of new bone tissue so as to lengthen the extremities or bridge resected bone deficiencies. In addition to the now-established intramedullary techniques, two different fixator systems are in use [50].

Furthermore, thumb amputation is a major cause of hand dysfunction, and the treatment for distal thumb amputations remains controversial. However, for reconstruction in cases of distal thumb amputations, distraction lengthening of the proximal phalanx can be used to improve absolute length, web space, and grip distance. The technique is safe and effective, improves functionality/cosmesis, and offers a low complication risk [51]. Digital distraction and second-stage bone graft is an effective method to compensate disabilities caused by lack of finger length. It could be an alternative plan for patients with thumb deficiency instead of toe-to-thumb transplant and patients with finger deficiency instead of ray resection [52]. Metacarpal and phalangeal distraction lengthening is an effective but demanding technique for ray reconstruction in congenital malformations of the hand. It is possible to lengthen a bone by more than $100 \%$. Complications are common, but in most cases easy to handle [53].

\section{Prosthetic Fitting}

Prostheses contrariwise offer the capacity to repair hand motor function the hazard of immunosuppression. Myoelectric prostheses have ever more advanced ergonomic and functional characteristics [54]. Prosthetic fitting with myoelectric instruments is the typical of carefulness in hand amputees [55]. Adjusting the prosthesis for a below-elbow amputee is frequently intuitive and easy to acquire 
in a sufficient rehabilitation setting. No additional surgery is required for fitting the below-elbow amputee with a prosthetic mean, and patients can return to close ordinary life realistically fast. Whereas, the control of artificial limbs is limited by the link between the patient and the prosthesis, rising computing power and the capability to decipher bio-signals results in increasingly accepted movements [54] [55]. Even so, prostheses usage is challenging in activities such as grooming, which may result in uneasiness at the stump region, and instruments need to be serviced on a regular basis. This results in abandonment of the prosthetic expedient in $20 \%$ of upper-limb amputees [56].

Even though, there are several studies investigated dissimilarities between replantation and prostheses, none of these has studied the functional and quality of life outcomes of transplanted and prosthetic limbs together [57] [58]. The recommendation for such studies has been emphasized by the specialist community [59]. In a multi-center cohort study comparing the functional outcomes of patients whose hands were reconstructed either by transplantation or prosthetic fitting from three different centers in Austria and Poland [60]. Prosthesis usage is extremely challenging for activities like grooming, swimming or sleeping and about $20 \%$ of upper-limb amputees do not use their prostheses [58] [61]. However, it has been shown, that active usage of prostheses inspires sustained acceptance, with lesser rejection-rates next to initial prosthetic fitting [58]. Prostheses rejecters report discomfort, lack of functional advantage, excessive weight, and repetitive necessity for repair and deficiency of sensory response as the leading causes for ceasing usage [61]. Notably, prosthetic fitting has no systemic side-effects. It delivers a rapid, continuous and to a great range expectable consequence, which experienced patients may further develop.

With regard to the spacious sensory ability of the hand, with all its diverse modalities of touch, vibration, proprioception, pain and temperature, undoubtedly a transplanted hand is the far superior option compared to the existing generation of prostheses. Even so, in unilateral amputees, irrespective of reconstructive method, the other healthy hand will constantly has superior functional competences. Actually, unilateral amputees with one surviving healthy hand, which come to be main, can generally carry out up to $90 \%$ of the activities of daily living [62].

Prosthetic fitting can be done as early as three months post-amputation, after swelling of the stump has settled and atrophy of the muscles is stable. This delivers a persistent and great expectable outcomes, which can be additionally enhanced over time [55]. Prosthetic rehabilitation commonly starts a few weeks next to surgery and at best even before prosthetic fitting [63]. As standard prostheses are organized by two independent (mostly antagonistic) myoelectric signals, the voluntary contraction of the parallel muscles is trained in therapy. Using electromyography (EMG) biofeedback instruments, this can similarly be completed without a prosthesis. Amputees customarily learn how to control the two myoelectric signals within a few therapy sessions [60]. 


\section{Hand Salvage}

Historically, amputation surgery is treatment of choice for many patients with hand disorders that requires surgical intervention. But in recent years and with advances in diagnostic imaging, reconstructive microsurgery, and efficacy of multi-disciplinary team, hand salvage choice is largely expanding [64]. Awareness of the option of salvage should be spread among healthcare staffs and the necessity for immediate attention by a multispeciality team is encouraged [65].

Several factors have been implicated in the successful salvage including; bone, fixation, tendon and muscle repair followed by microsurgical artery, nerve and vein repair, and finally skin closure. The hand is placed in a splint and the patient is monitored closely for circulatory changes in the fingers during the post-operative period. Moreover the success rates of hand salvage depends on other factors including; the importance of the part, level of injury, expected return of function, and mechanism of injury. Also the existence of associated injuries or preexisting illnesses, vascular/nerve injuries at multiple levels and patients who are mentally unstable may lead to poor outcomes [66]. However, the modern developments in microsurgical techniques and the related technologies and a superior understanding of microvascular anatomy have permitted us to modify flaps to the specific needs of the patients and to achieve a lower donor site morbidity. Improved communication between the specialties of the multidisciplinary treatment team has also improved outcomes [67].

Furthermore, Hand salvage and reconstruction following trauma and oncologic resection often dictates the use of innovative reconstructive techniques. Preservation of functional anatomy is paramount to success in this clinical setting. The free anterolateral thigh flap is a versatile flap that can be used as an innovative solution for hand salvage where vascular anatomy and soft tissue need to be restored [8].

\section{Conclusions}

Hand transplantation represents an exceptional approach of repairing a hand functional and sensory, as well as, psychosocial aspects including the rebuilding of bodily integrity, strength and even a sense of psychological closure associated with the primary traumatic incident. Such factors need to be remembered in the choice-making course leading to patient selection. If immunosuppression is accepted by the patient in post-operative rehabilitation, hand restoration is best succeeded with hand transplantation. In bilateral below-elbow amputees the advantages of functional and sensory renovation may compensate the risks of life-long immunosuppression. In unilateral below-elbow amputees, a prosthesis represents a suitable mean supporting the residual limb. Unilateral amputees are capable of compensating the bulk of the functional insufficiency using their healthy hand and a prosthesis.

The successful generation of donor-specific tolerance would prevent the harmfulness related to non-specific immunosuppression and may remove the 
possibility of subsequent rejection. Both biological and methodical developments will offer innovative options in this context. Moreover, future advances in prosthetic technology will have great influence on the role of hand transplantations, as well as bone lengthening.

\section{Disclosure of Interest}

The authors report no conflicts of interest.

\section{References}

[1] Meyer, T.M. (2003) Psychological Aspects of Mutilating Hand Injuries. Hand Clinics, 19, 41-49. http://www.ncbi.nlm.nih.gov/pubmed/12683445 https://doi.org/10.1016/S0749-0712(02)00056-2

[2] Herndon, J.H. (2000) Composite-Tissue Transplantation-A New Frontier. The New England Journal of Medicine, 343, 503-505. https://doi.org/10.1056/NEJM200008173430710

[3] Lanzetta, M., Nolli, R., Borgonovo, A., Owen, E.R., Dubernard, J.M., Kapila, H., et al. (2001) Hand Transplantation: Ethics, Immunosuppression and Indications. Journal of Hand Surgery (European Volume), 26, 511-516. https://doi.org/10.1054/jhsb.2001.0635

[4] Adani, R., Tarallo, L., Caccese, A.F., Delcroix, L., Cardin-Langlois, E. and Innocenti, M. (2014) Microsurgical Soft Tissue and Bone Transfers in Complex Hand Trauma. Clinics in Plastic Surgery, 41, 361-383. https://doi.org/10.1016/j.cps.2014.03.002

[5] Adani, R., Tarallo, L., Marcoccio, I., Cipriani, R., Gelati, C. and Innocenti, M. (2005) Hand Reconstruction Using the Thin Anterolateral Thigh Flap. Plastic and Reconstructive Surgery, 116, 467-473.

[6] Baccarani, A., Follmar, K.E., De Santis, G., Adani, R., Pinelli, M., Innocenti, M., et al. (2007) Free Vascularized Tissue Transfer to Preserve Upper Extremity Amputation Levels. Plastic and Reconstructive Surgery, 120, 971-981. https://doi.org/10.1097/01.prs.0000256479.54755.f6

[7] Green, S.W., Hotckiss, D.P., Pederson, R.N. and Wolfe, W.C. (2005) Green's Operative Hand Surgery. 5th Edition, Churchill Livingstone: Elsevier, 1569-1586.

[8] Kells, A.F., Broyles, J.M., Simoa, A.F., Lewis, V.O. and Sacks, J.M. (2013) Anterolateral Thigh Flow-Through Flap in Hand Salvage. Eplasty, 13, e19.

[9] Farina, D. and Aszmann, O. (2014) Bionic Limbs: Clinical Reality and Academic Promises. Science Translational Medicine, 6, 257ps12. https://doi.org/10.1126/scitranslmed.3010453

[10] Vilkki, S.K. and Kotkansalo, T. (2007) Present Technique and Long-Term Results of Toe-to-Antebrachial Stump Transplantation. Journal of Plastic, Reconstructive \& Aesthetic Surgery, 60, 835-848. https://doi.org/10.1016/j.bjps.2007.02.018

[11] Salminger, S., Roche, A.D., Sturma, A., Mayer, J.A. and Aszmann, O.C. (2016) Hand Transplantation versus Hand Prosthetics: Pros and Cons. Current Surgery Reports, 4, 8. https://doi.org/10.1007/s40137-016-0128-3

[12] Benatar, D. and Hudson, D.A. (2002) A Tale of Two Novel Transplants Not Done: The Ethics of Limb Allografts. BMJ, 324, 971-973. https://doi.org/10.1136/bmj.324.7343.971

[13] Lerman, O.Z., Kovach, S.J. and Levin, L.S. (2011) The Respective Roles of Plastic and Orthopedic Surgery in Limb Salvage. Plastic and Reconstructive Surgery, 127, 
215S-227S. https://doi.org/10.1097/PRS.0b013e3182006962

[14] American Society for Surgery of the Hand. About Hand Surgery. http://www.assh.org/handcare/About-Hand-Surgery

[15] Lalonde, D.H. (2011) Reconstruction of the Hand with Wide Awake Surgery. Clinics in Plastic Surgery, 38, 761-769. https://doi.org/10.1016/j.cps.2011.07.005

[16] Billig, J., Johnson, S.P., Ogawa, T. and Chung, K.C. (2016) Vascularized Composite Tissue Part Transfer for Central Hand Defect Reconstruction: Case Report. The Journal of Hand Surgery, 41, 76-80. https://doi.org/10.1016/j.jhsa.2015.10.025

[17] Marchessault, J.A., McKay, P.L. and Hammert, W.C. (2011) Management of Upper Limb Amputations. Journal of Hand Surgery, 36, 1718-1726. https://doi.org/10.1016/j.jhsa.2011.07.025

[18] Solarz, M.K., Thoder, J.J. and Rehman, S. (2016) Management of Major Traumatic Upper Extremity Amputations. Orthopedic Clinics of North America, 47, 127-136. https://doi.org/10.1016/j.ocl.2015.08.013

[19] Lalonde, D., Eaton, C., Amadio, P. and Jupiter, J. (2015) Wide-Awake Hand and Wrist Surgery: A New Horizon in Outpatient Surgery. Instructional Course Lectures, 64, 249-259.

[20] Malt, R.A. and Mckhann, C. (1964) Replantation of Severed Arms. JAMA, 189, 716-722.

[21] D’Addato, M., Pedrini, L., Bertoni, M., Stella, A., Vitacchiano, G., Sardella, L., et al. (1989) Traumatic Amputation of the Upper Limb: Replantation of the Arm. The Journal of Trauma, 29, 876-879. https://doi.org/10.1097/00005373-198906000-00029

[22] Jackson, A., Reilly, M. and Watson, S. (1992) Radiological Appearances Following Limb Replantation: A Report of 5 Cases. Skeletal Radiology, 21, 155-159. https://doi.org/10.1007/BF00242128

[23] Battiston, B., Tos, P., Clemente, A. and Pontini, I. (2007) Actualities in Big Segments Replantation Surgery. Journal of Plastic, Reconstructive \& Aesthetic Surgery, 60, 849-855. https://doi.org/10.1016/j.bjps.2007.02.017

[24] The Hoang, N., Hai, L.H., Staudenmaier, R. and Hoehnke, C. (2009) Complete Middle Forearm Amputations after Avulsion Injuries-Microsurgical Replantation Results in Vietnamese Patients. The Journal of Trauma, 66, 1167-1172. https://doi.org/10.1097/TA.0b013e318173f846

[25] Sugun, T.S., Ozaksar, K., Ada, S., Kul, F., Ozerkan, F., Kaplan, I., et al. (2009) Long-Term Results of Major Upper Extremity Replantations. Acta Orthopaedica et Traumatologica Turcica, 43, 206-213. https://doi.org/10.3944/AOTT.2009.206

[26] Wright, T.W., Hagen, A.D. and Wood, M.B. (1995) Prosthetic Usage in Major Upper Extremity Amputations. Journal of Hand Surgery, 20, 619-622. https://doi.org/10.1016/S0363-5023(05)80278-3

[27] Elliott, R.M., Tintle, S.M. and Levin, L.S. (2014) Upper Extremity Transplantation: Current Concepts and Challenges in an Emerging Field. Current Reviews in Musculoskeletal Medicine, 7, 83-88. https://doi.org/10.1007/s12178-013-9191-x

[28] Piza-Katzer, H. (2008) The Hand-Handless-Prostheses. Handchirurgie, Mikrochirurgie, Plastische Chirurgie, 40, 2-3.

[29] Ninkovic, M., Weissenbacher, A., Gabl, M., Pierer, G., Pratschke, J., Margreiter, R., et al. (2011) Functional Outcome after Hand and Forearm Transplantation: What Can Be Achieved? Hand Clinics, 27, 455-465.

https://doi.org/10.1016/j.hcl.2011.08.005 
[30] Gilbert, R. (1964) Transplant Is Successful with a Cadaver Forearm. Medical Tribune and Medical News, 5, 20-23.

[31] Schuind, F., Abramowicz, D. and Schneeberger, S. (2007) Hand Transplantation: The State-of-the-Art. Journal of Hand Surgery (European Volume), 32, 2-17. https://doi.org/10.1016/j.jhsb.2006.09.008

[32] Dubernard, J.M., Owen, E., Herzberg, G., Lanzetta, M., Martin, X., Kapila, H., Dawahra, M. and Hakim, N.S. (1999) Human Hand Allograft: Report on First 6 Months. The Lancet, 353, 1315-1320. https://doi.org/10.1016/S0140-6736(99)02062-0

[33] Kanitakis, J., Jullien, D., Petruzzo, P., Hakim, N., Claudy, A., Revillard, J.P., Owen, E. and Dubernard, J.M. (2003) Clinicopathologic Features of Graft Rejection of the First Human Hand Allograft. Transplantation, 76, 688-693. https://doi.org/10.1097/01.TP.0000079458.81970.9A

[34] Hautz, T., Engelhardt, T.O., Weissenbacher, A., Kumnig, M., Zelger, B., Rieger, M., et al. (2011) World Experience after More than a Decade of Clinical Hand Transplantation: Update on the Innsbruck Program. Hand Clinics, 27, 423-431. https://doi.org/10.1016/j.hcl.2011.07.004

[35] Hettiaratchy, S. and Butler, P.E. (2003) Extending the Boundaries of Transplantation. BMJ, 326, 1226-1227. https://doi.org/10.1136/bmj.326.7401.1226

[36] Petruzzo, P., Lanzetta, M., Dubernard, J.M., Landin, L., Cavadas, P., Margreiter, R., et al. (2010) The International Registry on Hand and Composite Tissue Transplantation. Transplantation, 90, 1590-1594. https://doi.org/10.1097/TP.0b013e3181ff1472

[37] Petruzzo, P. and Dubernard, J.M. (2011) The International Registry on Hand and Composite Tissue Allotransplantation. Clinical Transplantation, 2011, 247-253.

[38] Brandacher, G., Ninkovic, M., Piza-Katzer, H., Gabl, M., Hussl, H., Rieger, M., et al. (2009) The Innsbruck Hand Transplant Program: Update at 8 Years after the First Transplant. Transplantation Proceedings, 41, 491-494. https://doi.org/10.1016/j.transproceed.2009.01.013

[39] Breidenbach, W.C., Gonzales, N.R., Kaufman, C.L., Klapheke, M., Tobin, G.R. and Gorantla, V.S. (2008) Outcomes of the First 2 American Hand Transplants at 8 and 6 Years Posttransplant. Journal of Hand Surgery, 33, 1039-1047. https://doi.org/10.1016/j.jhsa.2008.02.015

[40] Cavadas, P.C., Ibáñez, J., Thione, A. and Alfaro, L. (2011) Bilateral Trans-Humeral Arm Transplantation: Result at 2 Years. American Journal of Transplantation, 11, 1085-1090. https://doi.org/10.1111/j.1600-6143.2011.03503.x

[41] Stangl, M.J., Biemer, E., Nerlich, A., et al. (2012) Three Year Immunological Follow up of the First Bilateral Arm Transplant World Wide: 1817. Transplantation, 94, 346. https://doi.org/10.1097/00007890-201211271-00641

[42] Jensen, S.E., Butt, Z., Bill, A., Baker, T., Abecassis, M.M., Heinemann, A.W., Cella, D. and Dumanian, G.A. (2012) Quality of Life Considerations in Upper Limb Transplantation: Review and Future Directions. Journal of Hand Surgery, 37, 2126-2135. https://doi.org/10.1016/j.jhsa.2012.06.010

[43] Brouha, P., Naidu, D., Cunningham, M., Furr, A., Majzoub, R., Grossi, F.V., et al. (2006) Risk Acceptance in Composite-Tissue Allotransplantation Reconstructive Procedures. Microsurgery, 26, 144-149.https://doi.org/10.1002/micr.20227

[44] Brandacher, G., Gorantla, V.S. and Lee, W.P. (2010) Hand Allotransplantation. Seminars in Plastic Surgery, 24, 11-17. https://doi.org/10.1055/s-0030-1253243

[45] Birch, R. (2011) Nerve Repair. In: Wolfe, S.W., Hotchkiss, R.N., Pederson, W.C. 
and Kozin, S.H., Eds., Green's Operative Hand Surgery, Elsevier, Philadelphia, 1035-1074.

[46] Bíró, V. (2012) Advances in Reconstructive Options of Nerve Injuries in the Hand. Orvosi Hetilap, 153, 1767-1778. https://doi.org/10.1556/OH.2012.29480

[47] Sabongi, R.G., De Rizzo, L.A., Fernandes, M., Valente, S.G., Gomes dos Santos, J.B., Faloppa, F. and Leite, V.M. (2014) Nerve Regeneration: Is There an Alternative to Nervous Graft? Journal of Reconstructive Microsurgery, 30, 607-616. https://doi.org/10.1055/s-0034-1372477

[48] Schmauss, D., Finck, T., Liodaki, E., Stang, F., Megerle, K., Machens, H.G. and Lohmeyer, J.A. (2014) Is Nerve Regeneration after Reconstruction with Collagen Nerve Conduits Terminated after 12 Months? The Long-Term Follow-Up of Two Prospective Clinical Studies. Journal of Reconstructive Microsurgery, 30, 561-568. https://doi.org/10.1055/s-0034-1375237

[49] Gubin, A.V., Borzunov, D.Y., Marchenkova, L.O., Malkova, T.A. and Smirnova, I.L. (2016) Contribution of G.A. Ilizarov to Bone Reconstruction: Historical Achievements and State of the Art. Strategies in Trauma and Limb Reconstruction, 11, 145-152. https://doi.org/10.1007/s11751-016-0261-7

[50] Reitenbach, E., Rödl, R., Gosheger, G., Vogt, B. and Schiedel, F. (2016) Deformity Correction and Extremity Lengthening in the Lower Leg: Comparison of Clinical Outcomes with Two External Surgical Procedures. SpringerPlus, 5, 2003. https://doi.org/10.1186/s40064-016-3666-3

[51] Cansü, E., Ünal, M.B., Parmaksızoğlu, F. and Gürcan, S. (2015) Distraction Lengthening of the Proximal Phalanx in Distal Thumb Amputations. Acta Orthopaedica et Traumatologica Turcica, 49, 227-232. https://doi.org/10.3944/AOTT.2015.14.0292

[52] Ding, Z., Zhu, X., Fu, K. and Zheng, X. (2017) Digital Lengthening to Treat Finger Deficiency: An Experience of 201 Digits in 104 Patients. BioMed Research International, 2017, Article ID: 4934280. https://doi.org/10.1155/2017/4934280

[53] Mann, M., Hülsemann, W., Winkler, F. and Habenicht, R. (2016) Distraction Osteogenesis Is an Effective Method to Lengthen Digits in Congenital Malformations. Handchirurgie, Mikrochirurgie, Plastische Chirurgie, 48, 48-52.

[54] Roche, A.D., Rehbaum, H., Farina, D. and Aszmann, O.C. (2014) Prosthetic Myoelectric Control Strategies: A Clinical Perspective. Current Surgery Reports, 2, 44. https://doi.org/10.1007/s40137-013-0044-8

[55] Salminger, S., Sturma, A., Herceg, M., Riedl, O., Bergmeister, K. and Aszmann, O.C. (2015) Prosthetic Reconstruction in High Amputations of the Upper Extremity. Orthopade, 44, 413-418. https://doi.org/10.1007/s00132-015-3113-0

[56] Biddiss, E.A. and Chau, T.T. (2007) Upper Limb Prosthesis Use and Abandonment: A Survey of the Last 25 Years. Prosthetics and Orthotics International, 31, 236-257. https://doi.org/10.1080/03093640600994581

[57] Agnew, S.P., Ko, J., De La Garza, M., Kuiken, T. and Dumanian, G. (2012) Limb Transplantation and Targeted Reinnervation: A Practical Comparison. Journal of Reconstructive Microsurgery, 28, 63-68. https://doi.org/10.1055/s-0031-1281522

[58] Jablecki, J., Kaczmarzyk, L., Patrzalek, D., Domanasiewicz, A. and Chełmoński, A. (2009) A Detailed Comparison of the Functional Outcome after Midforearm Replantations versus Midforearm Transplantation. Transplantation Proceedings, 41, 513-516. https://doi.org/10.1016/j.transproceed.2009.01.006

[59] Kay, S. and Wilks, D. (2013) Invited Comment: Vascularized Composite Allotransplantation: An Update on Medical and Surgical Progress and Remaining Chal- 
lenges. Journal of Plastic, Reconstructive \& Aesthetic Surgery, 66, 1456-1457. https://doi.org/10.1016/j.bjps.2013.04.065

[60] Salminger, S., Sturma, A., Roche, A.D., et al. (2016) Functional and Psychosocial Outcomes of Hand Transplantation Compared with Prosthetic Fitting in Below-Elbow Amputees: A Multicenter Cohort Study. PLOS ONE, 11, e0162507. https://doi.org/10.1371/journal.pone.0162507

[61] Biddiss, E. and Chau, T. (2007) Upper-Limb Prosthetics: Critical Factors in Device Abandonment. American Journal of Physical Medicine \& Rehabilitation, 86, 977-987. https://doi.org/10.1097/PHM.0b013e3181587f6c

[62] Bhaskaranand, K., Bhat, A.K. and Acharya, K.N. (2003) Prosthetic Rehabilitation in Traumatic Upper Limb Amputees (an Indian Perspective). Archives of Orthopaedic and Trauma Surgery, 123, 363-366. https://doi.org/10.1007/s00402-003-0546-4

[63] Miguelez, J.M. (2002) Critical Factors in Electrically Powered Upper-Extremity Prosthetics. Journal of Prosthetics and Orthotics, 14, 36-38. https://doi.org/10.1097/00008526-200203000-00010

[64] Leit, M.E. and Tomaino, M.M. (2004) Principles of Limb Salvage Surgery of the Upper Extremity. Hand Clinics, 20, 167-179. https://doi.org/10.1016/j.hcl.2004.03.001

[65] Nanda, V., Jacob, J., Alsafy, T., Punnoose, T., Sudhakar, V.R. and Iyasere, G. (2011) Replantation of an Amputated Hand: A Rare Case Report and Acknowledgement of a Multidisciplinary Team Input. Oman Medical Journal, 26, 278-282. https://doi.org/10.5001/omj.2011.68

[66] Vanstraelen, P., Papini, R.P., Sykes, P.J. and Milling, M.A. (1993) The Functional Results of Hand Replantation. The Chepstow Experience. Journal of Hand Surgery (European Volume), 18, 556-564. https://doi.org/10.1016/0266-7681(93)90003-X

[67] Heller, L. and Kronowitz, S.J. (2006) Lower Extremity Reconstruction. Journal of Surgical Oncology, 94, 479-489. https://doi.org/10.1002/jso.20485 